\title{
Heart Rate Variability and Atria Function in Children at Late Follow-Up Evaluation After Atrioventricular Node Slow-Pathway Radiofrequency Ablation
}

\author{
Rima Sileikiene $\cdot$ Jolanta Vaskelyte $\cdot$ Vaida Mizariene $\cdot$ \\ Irena Nedzelskiene • Raimonda Verseckaite - Renaldas Jurkevicius • \\ Dalia Baksiene $\cdot$ Viktorija Sileikyte $\cdot$ Rimantas Kevalas
}

Received: 19 January 2011/ Accepted: 22 March 2011/Published online: 11 April 2011

(C) Springer Science+Business Media, LLC 2011

\begin{abstract}
This study was designed to assess the changes in the conductive system, autonomic dysfunction, and global and regional function of the atria and ventricles in children late after slow-pathway radiofrequency ablation (RFA). The study enrolled 22 children, who has successfully undergone RFA 2 to 5 years previously (RFA group) and 20 healthy children (control group). Electrophysiologic study was performed for the RFA group. Holter monitoring and echocardiography were performed for all the children. At a late follow-up assessment, the RFA children were free of paroxysms, whereas 8 of the 22 children (36\%) reported transient palpitations. Both mean and maximal heart rates (HR) were significantly increased, whereas indices of HR variability (\% of succesive normal sinus RR intervals exceeding $50 \mathrm{~ms}$ [pNN50], root mean square of the succesive normal sinus RR interval difference [rMSSD], highfrequency component [HFC]) were significantly decreased in the RFA group compared with preablation and control data. Left atrial (LA) and right atrial (RA) volumes were significantly higher, and atria deformation indices were significantly lower in the RFA group. Correlations were found between the mean HR and the volumes of LA $(r=0.477 ; p<0.001)$ and RA $(r=0.512 ; p<0.001)$. A negative correlation between the maximal LA volume and the longitudinal strain rate (SR) during relaxation $(r=$ $-0.476 ; p=0.03$ ) and a positive correlation between the minimal LA volume and both longitudinal SR $(r=0.361$; $p=0.03)$ and strain $(\varepsilon)(r=0.375 ; p=0.024)$ during
\end{abstract}

R. Sileikiene $(\bowtie) \cdot J$. Vaskelyte · V. Mizariene

I. Nedzelskiene · R. Verseckaite - R. Jurkevicius .

D. Baksiene · V. Sileikyte $\cdot$ R. Kevalas

Department of Children Diseases, Lithuanian University

of Health Sciences, Eiveniu 2, Kaunas, LT 50009, Lithuania

e-mail: rima.sileikiene@kmuk.lt contraction were shown. These data suggest a possible link between atrial dysfunction and the hyperadrenergic state after RFA.

Keywords Children - Echocardiography - Heart rate · Radiofrequency ablation $\cdot$ Speckle tracking

Supraventricular tachycardias (atrioventricular reentrant tachycardia due to accessory pathways and atrioventricular nodal reentrant tachycardia) are common in children. During the past decade, transcatheter radiofrequency ablation (RFA) of supraventricular tachycardia in children became a method of choice due to its safety and effectiveness [11].

Alterations of heart rate (HR) and the presence of persistent, innapropriate sinus tachycardia, particularly after atrioventricular (AV) node slow-pathway ablation, have been reported for a variable percentage of patients [8-10]. It is suggested that disturbances of autonomic tone may be a contributing factor [9].

It remains unclear whether increased HR and frequent epizodes of sinus tachycardia after RFA have any influence on the systolic and diastolic function of the heart. Current conventional echocardiographic parameters assess only global left ventricular function, which are not always sensitive. Even in patients with symptoms of heart failure, they may remain within normal limits.

Assessment of regional atrial and ventricular function may provide important diagnostic information. The development of new echocardiographic techniques such as two-dimensional (2D) speckle-tracking echocardiography (2D STE) allows assessment of regional systolic and diastolic heart function, atrial and ventricular deformation parameters, speckle tracking-derived velocity, strain $(\varepsilon)$, and strain rate (SR) $[2,4,18]$. 
Strain rate, which reflects the rate of myocardial deformation, has been developed by estimating the spatial gradients in myocardial velocities, whereas $\varepsilon$, its integral, determines the total amount of local tissue deformation [4, 17]. Both are independent of overall heart motion, cardiac rotation, or motion induced by contraction in adjacent myocardial segments and thus are the true measure of local deformation. There are no data on subclinical changes in the systolic and diastolic functions of the heart in children who have undergone transcatheter RFA.

This study was designed to assess HR variability (HRV) using ambulatory Holter monitoring, AV node conduction determined by electrophysiologic transesophageal examination, and ventricular and atrial function determined by 2D STE in children at late follow-up assessment after RFA of the AV node slow pathway.

\section{Materials and Methods}

\section{Study Population}

The study group consisted of 42 subjects including 20 healthy children (control group) (10 boys) with a mean age of $16.3 \pm 1.6$ years and 22 children (11 boys) with mean age of $16.59 \pm 2.44$ years who underwent successful AV node slow-pathway RFA 2 to 5 years previously (RFA group). During the period 2000-2005, RFA of the AV node slow pathway was performed for 40 children due to typical AV nodal reentrant tachycardia. For 25 patients, modification of the slow pathway was performed, and for 15 patients, slow-pathway ablation was completed. The mean procedure time was $215 \pm 64 \mathrm{~min}$, and the mean number of applications was 4 or 5 . Only two minor complications (5\%), hematoma and phlebitis, were reported.

At the late follow-up assessment, 22 children were investigated (20 for whom the slow pathway was modified and 2 for whom it was completely eliminated). The remaining 18 children refused to participate in the study or were older than 18 years. Before treatment, the children experienced paroxysms of tachycardia with a mean duration of $57 \pm 41.04 \mathrm{~min}$. The mean HR during the paroxysm was $196.6 \pm 33.1$ beats per minute (bpm), and the mean rate of paroxysms was $3.25 \pm 1.56$ per month.

At the study time (late follow-up assessment after RFA), all the children were free of paroxysms except for eight children who experienced transient palpitations and did not use any medications. No signs of heart disease were detected by physical examination, electrocardiogram (ECG), or transthoracic conventional echocardiography. The healthy children (control group) had no complaints, no symptoms of heart failure, no history of cardiac rhythm disturbance, and no evidence of heart disease by physical examination, ECG, transthoracic echocardiography (no signs of left ventricular [LV] or right ventricular [RV] hypertrophy, valvular disease, or wall motion abnormalities), and they did not use any medications.

The two groups did not differ significantly in terms of age, body surface area, or body mass index (Table 2). The control group underwent 12-lead ECG ambulatory Holter monitoring and echocardiographic investigation. Due to discomfort of the electrophysiologic study, the electrophysiologic transesophageal investigation was not performed for the control group. The RFA group underwent 12-lead ECG ambulatory Holter monitoring 1 to 2 days before RFA. Subsequently, late after RFA, they underwent echocardiographic and electrophysiologic transesophageal investigations.

The study protocol was approved by the Ethics Commitee of the Kaunas University of Medicine. Informed consent was obtained before the study from all the patients or their parents.

Electrophysiologic Transesophageal Examination of the Heart Conductive System

This examination was performed for the RFA patients. The patients were examined while lying with a multicontact electrode polyurethane electrode diagnostic multicontact (PEDM) inserted into the esophagus. One pair of electrodes was used for the registration of transesophageal ECG, and another pair was used for the transesophageal stimulation. A computerized electrophysiologic system (CardioLab; GE, Milwaukee, WI, USA) was used for transesophageal ECG recordings and protocols, and the electrophysiologic MedSystems computerized stimulator EP-4 (West Berlin, NJ, USA) was used for cardiac pacing.

The following parameters were measured during the examination: ECG, sinus cycle length, PR interval, AV conduction, $\mathrm{AV}$ conduction time, prolongation of $\mathrm{AV}$ conduction time by a jump ( $\geq 50 \mathrm{~ms}$, representing the manifestation of antegrade dual AV nodal pathways) using atrial incremental pacing, and the AV node refractory period (ERP), estimated by programmed atrial pacing, with coupling intervals decreased $10 \mathrm{~ms}$ until the AV node refractory period occurred. These parameters were compared with parameters obtained during diagnostic preablation electrophysiologic transesophageal examination.

\section{Holter Monitoring and HR Variability Analysis}

The examination was performed on an ambulatory basis using the commercially available MemoPort 2000/4000 software package system (Marquette Hellige Company, Northamptonshire, UK). Holter's monitor SRPL-10 (Northamptonshire, UK) (storing data on the hard disc) was used for 24-h ECG registration. Holter's monitor recorded 
three bipolar ECGs. The data then were transferred to the computer, and the analysis of the results was performed.

The following parameters of the recorded ECG were evaluated: minimal rate of the heart contractions (bpm) recorded during $24 \mathrm{~h}$ ( $\mathrm{HR}$ min), mean rate of the heart contractions (bpm) recorded during $24 \mathrm{~h}$ (HR mean), and maximal rate of the heart contractions (bpm) recorded during $24 \mathrm{~h}$ HR maximum (HR max).

The parameters of HRV were calculated in compliance with the recommendations of the American Heart Association and the European Society of Cardiology [1]. The analysis of HRV was performed when the range of ECG signals exceeded $100 \mathrm{~Hz}$. The ECG record was filtered, and only normal QRS complexes were analyzed. The ectopic atrial and ventricular complexes and the episodes of pauses were excluded.

To avoid the influence of ectopic impulses, arrhythmias, and artifacts on HRV parameters, interpolation was performed. Gaps in the R-R sequence due to rejections of complexes were filled in with automatically calculated R-R intervals during interpolation. The chosen quantified frequency of the R-R sequence was $292 \mathrm{~ms}$. The parabolic method was used for the de-trending. The Fourje fasttransformation method was used to calculate frequency parameters.

The following parameters were used for HRV analysis: time-domain indices: standard deviation of all normal sinus RR intervals over $24 \mathrm{~h}$ (ms) (SDNN), percentage of the succesive normal sinus RR intervals exceeding $50 \mathrm{~ms}(\%)$ (pNN50), and root mean square of the successive normal sinus RR interval difference (ms) (rMSSD). The frequency domain indices were the low-frequency component (LFC) (frequency range, $0.04-0.15 \mathrm{~Hz}$ ), the high-frequency component (HFC) (frequency range, $0.15-0.40 \mathrm{~Hz}$ ), and the total spectrum. The HR and HRV parameters for the RFA patients, obtained during the late postablation period, were compared with the preablation 24-h Holter recording data.

\section{Conventional Echocardiography}

Echocardiographic technique and calculations of morphometric parameters were performed in accordance with the recommendations of the American Society of Echocardiography 2005 [12]. The biplane Simpson's rule was used for calculation of the $\mathrm{LV}$ ejection fraction. Maximum left atrium (LA) and right atrium (RA) volumes were obtained from the 2D frame just before mitral valve opening. Minimal LA and RA volumes were obtained from the smallest volumes seen after atrial contraction.

\section{Automated Speckle-Tracking Imaging}

For 2D STE analysis, we used Vivid 7 (GE Vingmed Ultrasound AS, Horten, Norway) equipment. Tissue harmonic images were scanned at long-axis apical fourand two-chamber views with the M3S probe (GE, Parallel Design Inc., Phoenix, AZ, USA). For analysis of LV, RV, LA, and RA long-axis function, apical four- and twochamber views were used. The mean frame rate was 50 frames/s (range, 40-70 frames/s).

Digital loops were stored on the hard disc of the echocardiographic machine and transferred to a workstation (EchoPac PC, GE Vingmed Ultrasound AS, Horten, Norway) for offline analysis. A line was traced along the endocardium of the $\mathrm{LV}$ and $\mathrm{RV}$ at the frame where it was best defined. For atrial analysis, a line was drawn along the LA and RA endocardium when the atria were at their minimal volume after contraction. On the basis of this line, the computer automatically created a region of interest, and the software selected natural acoustic markers, moving with the tissue. Automatic frame-by-frame tracking of these markers during the heart cycle (2D STE method) yielded a measure of $\varepsilon$ and SR at any point of the myocardium.

The LV was divided into six long-axis segments in each view. The RV was divided into basal and middle segments of the lateral wall. The RA was divided into two long-axis segments (annular and middle) of the lateral wall, and the LA was divided into four long-axis segments (annular and middle) of the septum, lateral, anterior, and inferior walls. The superior or "roof" region of the atria was excluded because this segment is rather stationary and makes no contribution to the atrial motion or active contraction.

Analysis of Regional Ventricular and Atrial Longitudinal Function: Strain and Strain Rate

The four-chamber view of the heart was analyzed offline using Echo PAC software to assess the $\varepsilon$ and SR of the LV lateral wall, ventricular septum, RV lateral wall segments, RA lateral wall segments, atrial septum, and LA lateral wall segments. The apical two-chamber view was used to assess $\varepsilon$ and SR of the LV inferior and anterior wall segments and the LA inferior and anterior wall segments using the 2D STE method.

The SR is equivalent to the spatial gradient of pixel movements. It is characterized by the equation

$\mathrm{SR}=\mathrm{d}(\mathrm{r})-\mathrm{d}(\mathrm{r}+\Delta \mathrm{r}) / \Delta \mathrm{r}_{*} \mathrm{t}$,

where $\mathrm{d}$ is distance in movement, $\mathrm{r}$ is location in space, and $\mathrm{t}$ is time expressed as $\mathrm{s}^{-1}$ [2]. The time integral of incremental SR yields $\varepsilon$, defined as the fractional change from the original dimension of the percentage shortening or lengthening of the myocardium $[2,4,17]$ and calculated as

$\varepsilon=\mathrm{L}-\mathrm{L}_{0} / \mathrm{L}_{0}$,

where $\mathrm{L}$ and $\mathrm{L}_{0}$ are the lengths of an infinitesimal material line segment at end diastole and end systole, respectively. Three cardiac cycles were averaged. 
The EchoPac system calculates mean global $\varepsilon$ and SR values for whole predefined LV and RV as well as LA and RA segments. Lengthening is positive and shortening is negative in this description. Atrial $\varepsilon$ and SR values were measured during atrial contraction (time from the end of P-wave on ECG to mitral valve closure) and relaxation (time from mitral valve closure to aortic valve opening).

\section{Statistical Analysis}

Statistical analysis was performed with software SPPS version 14.0 (SPSS, Inc., Chicago, IL, USA). A $p$ value of 0.05 or less was considered significant. All parametric data were expressed as mean \pm standard deviation. When the distribution of variables was normal, Student's $t$ test was used to compare quantitative sizes of two independent samples. The Mann-Whitney $U$ test was used to compare non-normally distributed variables. For the normal distribution of quantitative dependent variables, Student's paired $t$ test was used, and for non-normal distribution, the nonparametric Wilcoxon test was used. Chi-square tests were used to compare frequencies of qualitative variables. Spearman correlation coefficients were obtained to describe relations of parameters for different methods to evaluate the systolic and diastolic functions of the heart.

Intraobserver variability was determined by one observer repeating the measurements of STE in five randomly selected subjects 1 month later. Agreement between the measurements was evaluated by linear regression analysis using the correlation coefficient. In addition, BlandAltman analysis was used to determine the bias and limits of agreement between the corresponding measurements. The significance of intertechnique biases was tested using paired $t$ tests.

\section{Results}

\section{Electrophysiologic Study}

At the late follow-up evaluation, 8 of the 22 RFA children (36\%) reported palpitations during their daily activity. The PR intervals were normal in all the RFA children. The sinus cycle length was shortened $(644.4 \pm 179.5$ vs $736.6 \pm$ $134 \mathrm{~ms}$ before ablation; $p<0.05$ ) and did not differ between the patients who had no complaints and those who experienced palpitations. At the follow-up evaluation, the slow pathway was observed for 20 patients (those who underwent modification of the slow pathway). Atrioventricular node supraventricular tachycardia could not be induced in any of the patients, and AV node conduction decreased significantly up to $146.3 \pm 28.5 \mathrm{bpm}$ compared with $190.9 \pm$ $31.4 \mathrm{bpm}$ before ablation $(p<0.001)$. The AV node ERP was prolonged significantly up to $351.0 \pm 82.1 \mathrm{~ms}$ compared with $248.3 \pm 36.6 \mathrm{~ms}$ before ablation $(p<0.001)$.

\section{Holter Monitoring}

\section{$H R$ and HR Variability Analysis}

At late follow-up evaluation, HR mean and HR max were significantly increased, whereas pNN50, rMSSD, and HFC were significantly decreased in the RFA children compared with preablation and control data (Table 1). Findings showed comparable SDNN between the groups. There were no changes in the LFC frequency domain or the total spectrum analysis. For the eight patients, who felt palpitations during their daily activity, the episodes of sinus tachycardia with an HR max of $144.3 \pm 14.2 \mathrm{bpm}$ and a mean duration of 1 to $2 \mathrm{~min}$ were registered on the Holter 24-h registrations.

\section{Conventional Echocardiographic Parameters}

Conventional echocardiographic parameters are presented in Table 2. The two groups did not differ significantly in LV dimensions, ejection fraction, or fractional shortening. The LV and RV inflow indices were comparable between the RFA and control groups, except that LV filling velocity during atrial contraction was decreased in the RFA group. The LA and RA volumes (minimum and maximum) and their indices were significantly higher in the RFA group.

To determine the causes of LA and RA dilation, correlations between atria volume and clinical parameters (age, weight, duration of disease, characteristics of paroxysms of AV tachycardia), HR parameters and functional parameters (LV and RV dimensions and function) were assessed. Correlations were found between the HR mean and the LA/RA maximal volumes $(r=0.477, p<0.001$ and $r=$ $0.512, p<0.001$, respectively) and minimal volumes $(r=0.416, p<0.001$ and $r=0.288, p<0.005$, respectively), the LA/RA maximal volume indices $(r=0.471$, $p<0.001$ and $r=0.550, p<0.001$, respectively), and the LA/RA minimal volume indices $(r=0.434, p=0.004$ and $r=0.397, p=0.009$, respectively).

\section{Longitudinal Strain and Strain Rate Parameters of the Ventricles and Atria}

All $\varepsilon$ and SR tracings were acceptable for the analysis of longitudinal atrial and ventricular $\varepsilon$ and SR. The LA and RA longitudinal $\varepsilon$ and SR are presented in Table 3 . The $\varepsilon$ values during atrial contraction were reduced in all the LA and RA wall segments in RFA group. During relaxation, $\varepsilon$ was reduced in all the LA and RA wall segments in the RFA group except for the LA middle segments of the 
Table 1 Heart rate and heart rate variability

\begin{tabular}{|c|c|c|c|c|c|}
\hline \multirow[t]{2}{*}{ Parameter } & \multicolumn{2}{|c|}{ RFA group $(n=22)$} & \multirow[t]{2}{*}{$p$ Value $^{\mathrm{b}}$} & \multirow[t]{2}{*}{ Control group $(n=20)$} & \multirow[t]{2}{*}{$*_{p}$ Value $^{c}$} \\
\hline & Preablation & Postablation & & & \\
\hline HR min & $51.25 \pm 5.0$ & $53.59 \pm 5.38$ & NS & $51.75 \pm 5.77$ & NS \\
\hline HR mean & $71.07 \pm 8.07$ & $78.72 \pm 5.34$ & $<0.001$ & $72.00 \pm 9.23$ & 0.002 \\
\hline HR max & $131.71 \pm 14.51$ & $143.91 \pm 13.05$ & 0.005 & $132.5 \pm 16.57$ & 0.008 \\
\hline SDNN (ms) & $159.36 \pm 25.7$ & $149.78 \pm 24.76$ & NS & $163.85 \pm 29.32$ & NS \\
\hline pNN50 (\%) & $26.64 \pm 7.03$ & $20.63 \pm 6.83$ & 0.006 & $26.20 \pm 8.15$ & 0.03 \\
\hline rMSSD (ms) & $49.72 \pm 11.68$ & $42.56 \pm 12.58$ & 0.034 & $51.2 \pm 14.5$ & 0.01 \\
\hline $\operatorname{LFC}\left(\mathrm{ms}^{2}\right)$ & $1,345.28$ & 1224.83 & NS & $1,523.83$ & NS \\
\hline $\mathrm{HFC}\left(\mathrm{ms}^{2}\right)$ & $1,032.59$ & 706.24 & 0.007 & $1,014.65$ & 0.027 \\
\hline Total spectrum $\left(\mathrm{ms}^{2}\right)$ & $6,134.44$ & $6,045.16$ & NS & $6,375.49$ & NS \\
\hline
\end{tabular}

$R F A$ radiofrequency ablation, $H R$ min minimal rate of the heart contractions (beats per minute [bpm]) recorded during $24 \mathrm{~h}, N S$ not significant by an independent two sampled test, HR mean mean rate of the heart contractions (bpm) recorded during $24 \mathrm{~h}, H R$ max maximal rate of the heart contractions (bpm) recorded during $24 \mathrm{~h}, S D N N$ standard deviation of all normal sinus RR intervals over $24 \mathrm{~h}$, pNN50 percentage of the succesive normal sinus RR intervals $>50 \mathrm{~ms}, r M S S D$ root mean square of the succesive normal sinus RR interval difference, $L F C$ low-frequency component (frequency range, $0.04-0.15 \mathrm{~Hz}$ ), $\mathrm{HFC}$ high-frequency component (frequency range, $0.15-0.40 \mathrm{~Hz}$ ), total spectrum

a Values are expressed as mean \pm standard deviation

b Preablation data compared with postablation data (values determined by paired Student's $t$ test)

c Postablation data compared with control group (values determined by unpaired Student's $t$ test)

Table 2 Conventional echocardiographic parameters ${ }^{\mathrm{a}}$

\begin{tabular}{|c|c|c|c|}
\hline Variable & Control group & RFA group postablation & $p$ Value \\
\hline Number & 20 & 22 & \\
\hline Age (years) & $16.3 \pm 1.6$ & $16.6 \pm 2.4$ & NS \\
\hline Body surface area $\left(\mathrm{m}^{2}\right)$ & $1.6 \pm 0.14$ & $1.6 \pm 1.86$ & NS \\
\hline BMI $\left(\mathrm{kg} / \mathrm{m}^{2}\right)$ & $20.69 \pm 2.56$ & $21.05 \pm 2.7$ & NS \\
\hline LV end-diastolic volume (ml) & $103.5 \pm 21.6$ & $104.5 \pm 20.63$ & NS \\
\hline LV end-systolic volume (ml) & $23.0 \pm 6.8$ & $24.4 \pm 8.7$ & NS \\
\hline LV ejection fraction $(\%)$ & $56.5 \pm 3.9$ & $54.5 \pm 3.97$ & NS \\
\hline LV fractional shortening (\%) & $45.3 \pm 4.6$ & $46.4 \pm 5.62$ & NS \\
\hline LV myocardial mass index $\left(\mathrm{g} / \mathrm{m}^{2}\right)$ & $86.2 \pm 3.6$ & $90.3 \pm 4.5$ & NS \\
\hline LV early filling velocity $(\mathrm{cm} / \mathrm{s})$ & $82.0 \pm 12.1$ & $88.1 \pm 7.2$ & NS \\
\hline LV filling velocity during atrial contraction $(\mathrm{cm} / \mathrm{s})$ & $55.4 \pm 8.0$ & $48.2 \pm 2.2$ & 0.01 \\
\hline LV early filling deceleration time (ms) & $162.8 \pm 31.9$ & $161.4 \pm 35.8$ & NS \\
\hline RV basal diameter (mm) & $28.3 \pm 2.3$ & $29.1 \pm 3.2$ & NS \\
\hline RV early filling velocity $(\mathrm{cm} / \mathrm{s})$ & $61.4 \pm 12.3$ & $58.8 \pm 11.0$ & NS \\
\hline Tricuspid annulus motion amplitude (mm) & $19.5 \pm 0.6$ & $21.4 \pm 0.4$ & NS \\
\hline Maximal LA volume (ml) & $28.0 \pm 8.7$ & $37.3 \pm 13.9$ & 0.024 \\
\hline Maximal LA volume index $\left(\mathrm{ml} / \mathrm{m}^{2}\right)$ & $16.7 \pm 6.0$ & $26.3 \pm 9.8$ & 0.002 \\
\hline Maximal RA volume (ml) & $16.0 \pm 6.7$ & $21.5 \pm 8.5$ & 0.047 \\
\hline Maximal RA volume index $\left(\mathrm{ml} / \mathrm{m}^{2}\right)$ & $16.0 \pm 6.6$ & $21.5 \pm 8.5$ & 0.05 \\
\hline Minimal LA volume (ml) & $11.65 \pm 2.25$ & $13.64 \pm 2.25$ & 0.007 \\
\hline Minimal LA volume index $\left(\mathrm{ml} / \mathrm{m}^{2}\right)$ & $7.16 \pm 1.3$ & $8.36 \pm 1.32$ & 0.005 \\
\hline Minimal RA volume (ml) & $12.15 \pm 4.5$ & $15.23 \pm 5.01$ & 0.043 \\
\hline Minimal RA volume index $\left(\mathrm{ml} / \mathrm{m}^{2}\right)$ & $7.41 \pm 2.52$ & $9.36 \pm 3.2$ & 0.035 \\
\hline
\end{tabular}

$N S$ not significant by an independent two-sampled test, $R F A$ radiofrequency ablation, $B M I$ body mass index, $L V$ left ventricular, $R V$ right ventricular, $L A$ left atrial, $R A$ right atrial

${ }^{\text {a }}$ Values are expressed as mean \pm standard deviation 
Table 3 Atrial longitudinal strain and strain rate ${ }^{\mathrm{a}}$

\begin{tabular}{|c|c|c|c|c|c|c|}
\hline \multirow[t]{2}{*}{ Parameters } & \multicolumn{3}{|l|}{ Contraction } & \multicolumn{3}{|l|}{ Relaxation } \\
\hline & $\begin{array}{l}\text { Control group } \\
(n=20)\end{array}$ & $\begin{array}{l}\text { RFA group } \\
\text { postablation } \\
(n=22)\end{array}$ & $p$ Value & $\begin{array}{l}\text { Control group } \\
(n=20)\end{array}$ & $\begin{array}{l}\text { RFA group } \\
\text { postablation } \\
(n=22)\end{array}$ & $p$ Value \\
\hline \multicolumn{7}{|l|}{$A 4 C$} \\
\hline \multicolumn{7}{|l|}{ AS annular seg } \\
\hline Strain $(\%)$ & $-5.54(2.0)$ & $-2.44(1.09)$ & $<0.001$ & $21.55(5.97)$ & $12.75(2.87)$ & $<0.001$ \\
\hline Strain rate $\left(\mathrm{s}^{-1}\right)$ & $-2.2(1.25)$ & $-1.05(0.37)$ & 0.001 & $1.43(1.3)$ & $1.08(0.96)$ & 0.02 \\
\hline \multicolumn{7}{|l|}{ AS middle seg } \\
\hline Strain $(\%)$ & $-5.57(2.94)$ & $-2.58(1.6)$ & 0.001 & $17.89(5.12)$ & $12.62(3.68)$ & 0.001 \\
\hline Strain rate $\left(\mathrm{s}^{-1}\right)$ & $-1.9(0.75)$ & $-1.25(0.36)$ & 0.003 & $1.86(0.73)$ & $1.66(0.96)$ & NS \\
\hline \multicolumn{7}{|c|}{ LA lateral wall annular seg } \\
\hline Strain $(\%)$ & $-5.63(2.8)$ & $-2.82(1.35)$ & $<0.001$ & $23.56(17.01)$ & $10.35(4.4)$ & 0.005 \\
\hline Strain rate $\left(\mathrm{s}^{-1}\right)$ & $-2.32(0.83)$ & $-1.48(0.5)$ & 0.001 & $1.66(0.44)$ & $1.3(0.58)$ & 0.001 \\
\hline \multicolumn{7}{|c|}{ LA lateral wall middle seg } \\
\hline Strain $(\%)$ & $-4.32(2.3)$ & $-2.67(1.24)$ & 0.001 & $19.54(11.32)$ & $9.37(4.10)$ & 0.02 \\
\hline Strain rate $\left(\mathrm{s}^{-1}\right)$ & $-2.14(0.9)$ & $-1.28(0.26)$ & 0.001 & $1.65(0.32)$ & $1.44(0.5)$ & NS \\
\hline \multicolumn{7}{|c|}{ RA lateral wall annular seg } \\
\hline Strain $(\%)$ & $-6.67(1.05)$ & $-4.33(1.6)$ & $<0.001$ & $24.02(10.88)$ & $15.39(5.29)$ & 0.006 \\
\hline Strain rate $\left(\mathrm{s}^{-1}\right)$ & $-2.22(1.8)$ & $-1.81(0.29)$ & 0.003 & $1.37(0.85$ & $1.31(0.1)$ & NS \\
\hline \multicolumn{7}{|c|}{ RA lateral wall middle seg } \\
\hline Strain $(\%)$ & $-5.05(1.96)$ & $-3.55(2.16)$ & 0.04 & $25.75(14.23)$ & $14.66(5.63)$ & 0.03 \\
\hline Strain rate $\left(\mathrm{s}^{-1}\right)$ & $-2.21(0.3)$ & $-2.03(0.4)$ & NS & $1.27(0.52)$ & $1.08(0.19)$ & NS \\
\hline \multicolumn{7}{|l|}{$A 2 C$} \\
\hline \multicolumn{7}{|c|}{ LA inferior wall annular seg } \\
\hline Strain $(\%)$ & $-4.61(3.07)$ & $-2.04(1.66)$ & 0.005 & $26.09(17.05)$ & $15.62(3.69)$ & 0.02 \\
\hline Strain rate $\left(\mathrm{s}^{-1}\right)$ & $-2.45(0.5)$ & $-1.88(0.42)$ & 0.001 & $1.59(0.1)$ & $1.36(0.26)$ & 0.02 \\
\hline \multicolumn{7}{|c|}{ LA inferior wall middle seg } \\
\hline Strain $(\%)$ & $-4.18(1.2)$ & $-2.79(0.55)$ & $<0.001$ & $22.34(6.08)$ & $18.76(5.37)$ & NS \\
\hline Strain rate $\left(\mathrm{s}^{-1}\right)$ & $-2.42(0.12)$ & $-2.12(0.71)$ & NS & $1.54(0.15)$ & $1.41(0.27)$ & NS \\
\hline \multicolumn{7}{|c|}{ LA anterior wall annular seg } \\
\hline Strain $(\%)$ & $-4.67(2.07)$ & $-3.11(1.2)$ & 0.014 & $24.14(11.83)$ & $15.08(3.43)$ & 0.005 \\
\hline Strain rate $\left(\mathrm{s}^{-1}\right)$ & $-2.26(0.77)$ & $-1.35(0.16)$ & 0.042 & $1.57(0.1)$ & $1.49(0.35)$ & NS \\
\hline \multicolumn{7}{|c|}{ LA anterior wall middle seg } \\
\hline Strain $(\%)$ & $-4.37(2.57)$ & $-2.88(1.02)$ & 0.038 & $19.22(7.04)$ & $15.37(3.96)$ & NS \\
\hline Strain rate $\left(\mathrm{s}^{-1}\right)$ & $-2.21(0.74)$ & $-1.49(0.4)$ & 0.002 & $1.51(0.38)$ & $1.51(0.39)$ & NS \\
\hline
\end{tabular}

$A 4 C$ apical four-chamber view, $A S$ atrial septum, seg segment, $N S$ not significant by an independent two-sampled test, $L A$ left atrium, $R A$ right atrium, $A 2 C$ apical two-chamber view

${ }^{a}$ Values are expressed as mean (standard deviation)

inferior and anterior walls. Longitudinal SR during atrial contraction was reduced in all the LA and RA walls in the RFA group except for the middle segments of the RA lateral wall and the LA inferior wall. Longitudinal SR during relaxation was reduced only in the annular segments of LA in the RFA group.

There was a negative correlation between maximal LA volume and LA longitudinal SR during relaxation $(r=-0.476, p=0.03)$ and a positive correlation between minimal LA volume and both LA longitudinal SR $(r=0.361, p=0.03)$ and $\varepsilon(r=0.375, p=0.024)$ during contraction.

Negative correlations were found between HR max and both $\varepsilon(r=-0.518, p=0.05)$ and SR $(r=-0.661$, $p=0.005)$ during relaxation of the LA lateral wall, and between HR max and SR $(r=-0.640, p=0.008)$ during contraction of the atrial septum. The LV and RV longitudinal deformation values were homogeneous for all the $\mathrm{LV}$ 
Table 4 Left and right ventricular global longitudinal strain and strain rate $\left(\mathrm{s}^{-1}\right)^{\mathrm{a}}$

\begin{tabular}{lccc}
\hline Parameters & Control group $(n=20)$ & RFA group $(n=22)$ & $p$ Value \\
\hline LV peak strain $(\%)$ & $-21.55(3.6)$ & $-20.77(3.8)$ & NS \\
LV peak systolic strain $(\%)$ & $-17.48(2.04)$ & $-18.17(3.03)$ & $-1.32(0.53)$ \\
LV peak systolic strain rate $\left(\mathrm{s}^{-1}\right)$ & $-1.23(0.46)$ & $1.86(0.25)$ & $\mathrm{NS}$ \\
LV early diastolic strain rate $\left(\mathrm{s}^{-1}\right)$ & $1.71(0.36)$ & $1.04(0.29)$ & $\mathrm{NS}$ \\
LV late diastolic strain rate $\left(\mathrm{s}^{-1}\right)$ & $0.95(0.43)$ & $-20.66(5.43)$ & $\mathrm{NS}$ \\
RV peak strain $(\%)$ & $-20.63(5.43)$ & $-19.54(5.38)$ & $\mathrm{NS}$ \\
RV peak systolic strain $(\%)$ & $-17.89(5.75)$ & $-1.25(0.65)$ & $\mathrm{NS}$ \\
RV peak systolic strain rate $\left(\mathrm{s}^{-1}\right)$ & $-1.33(0.6)$ & $1.67(0.39)$ & $\mathrm{NS}$ \\
RV early diastolic strain rate $\left(\mathrm{s}^{-1}\right)$ & $1.81(0.41)$ & $0.93(0.29)$ & $\mathrm{NS}$ \\
RV late diastolic strain rate $\left(\mathrm{s}^{-1}\right)$ & $1.03(0.44)$ & $\mathrm{NS}$ \\
\hline
\end{tabular}

$L V$ left ventricular, $N S$ not significant by an independent two-sampled test, $R V$ right ventricular

${ }^{\text {a }}$ Values are expressed as mean (standard deviation)

and RV segments, and there were no significant differences between the subjects of the two groups (Table 4).

\section{Reproducibility of Longitudinal Strain and Strain Rate Measurements}

Because continuous variables were distributed abnormally, parameters were transformed to logarithmic scale. The intraobserver variability with a $95 \%$ confidence interval was $-0.1(-0.91$ to -0.7$)$ for the atrial systolic longitudinal $\varepsilon$ and $-0.04(-0.11$ to -0.03$)$ for the atrial longitudinal systolic SR.

\section{Discussion}

The effectiveness of the treatment for supraventricular tachyarrhythmia using RFA in children is high, and the complication rate is low $[3,7]$. Usually, after successfully performed RFA, children have no reports of heart failure. They are considered as healthy and engage in sports activities.

In our study, all the RFA children at the late follow-up assessment were free of paroxysms and did not have any complaints except for eight children (36\%), who felt palpitations during their daily activity and presented with episodes of sinus tachycardia that had a mean duration of 1 to $2 \mathrm{~min}$ on the Holter 24-h monitoring. Electrophysiologic transesophageal examination did not show inducible supraventricular tachycardia in any of the children during the late follow-up period.

Compared with preablation data, R-R intervals were shorter in all the RFA children at the late follow-up assessment. The 24-h Holter monitoring showed that mean and maximal HR were increased, whereas the HRV parameters, including time domain indices (pNN50, rMSSD) and frequency domain index (HFC), which reflect the attenuation of parasympathetic tone, were decreased in the RFA children during the late postablation period. Echocardiographic examination showed increased atria volumes and reduced regional atrial myocardial deformation parameters ( $\varepsilon$ and SR), especially in annular segments of the atria, in the RFA children during the late postablation period.

The possible reason for the main findings is that HRV reflects attenuation of the parasympathetic tone and decreased atria function (increased atria volumes and reduced regional atrial myocardial deformation) late after RFA in the children of our study.

Changes in the autonomic tone have been described after fast- and slow-pathway ablation for AV node tachycardia $[8-10,16]$. In contrast to previous studies, which have shown changes immediately or the next day after RFA [14, 16, 19, 21], we found the changes in autonomic tone of the heart during the late follow-up period. Only two other studies have demonstrated changes in autonomic tone during a 6-month to 1-year follow-up period after accessory pathways and AV node slow-pathway RFA $[8,10]$.

Previous clinical and experimental studies have provided evidence that postprocedural expansion of myocardial radiofrequency lesions can occur. In an experimental study using young lambs, myocardial scar dimensions were reported to increase in a time-dependent manner up to 9 months after RFA, from $5.3 \pm 0.5 \mathrm{~mm}$ to $8.7 \pm 0.7 \mathrm{~mm}$ in atrium tissue and from $5.9 \pm 0.8 \mathrm{~mm}$ to $10.1 \pm 0.7 \mathrm{~mm}$ in ventricular tissue [15]. Moreover, the postinjury remodeling process includes compensatory myocyte hypertrophy in the myocardium remote from the scar [13]. Radiofrequency-induced lesions not only may directly interrupt anatomically distinct neural fibers, but they also 
may activate or inhibit reflex cardiac circuits [10]. Thus, parasympathetic denervation may be an explanation for the increased HR and inappropriate sinus tachycardia in these children. Experimental studies have shown that parasympathetic reinnervation usually requires only 6 weeks (in dogs) $[14,16]$. The possible explanation for the long-term changes in the autonomic tone after RFA may be a more pronounced lesion of RFA in a child heart, which is smaller and has thinner walls more vulnerable to injury.

Our study found correlations between mean HR and atria volumes, between LA volume and regional atrial deformation parameters, and between maximal HR and regional atrial deformation parameters. Correlations between LA volume, regional atrial deformation, and HR permit us to assume that inappropriate adrenergic response, elevated sympathetic tone, and inhomogeneity of parasympathetic innervation in the atria (regional differences in repolarization and conduction velocity) [10] late after AV node slow-pathway RFA may lead to the development of atrial dilation and dysfunction.

Assessment of regional atrial function using speckle tracking in children may provide more insights into atrial remodeling and may be helpful in many clinical conditions $[5,6,18,20,22]$. To our knowledge, this is the first study to assess atria morphology and regional deformation parameters after RFA of the AV node slow pathway in children.

In conclusion, increased mean and maximal HR, decreased HRV parameters, increased atria volumes, and decreased atria segmental deformation parameters at the late follow-up assessment for children who underwent RFA suggest a possible link between atrial dysfunction and the hyperadrenergic state after AV node slow-pathway RFA. Speckle-tracking echocardiography may be useful in the assessment of atria function in patients who have undergone RFA.

Changes in HRV and in atria function in a pediatric population late after RFA imply certain negative aspects of the RFA procedure. However, the clinical value of this finding has to be evaluated in experimental anatomic and further prospective clinical studies.

\section{Study Limitations}

Our study showed a hyperadrenergic state during the late AV node slow-pathway postablation period, and this finding may be qualified as partial autonomic neuropathy. Neurohumoral activation factors such as catecholamine, plasma natriuretic peptides, rennin activity, and aldosterone levels also are expected to be elevated. However, tests for these factors were not performed, and further investigations are needed.
Acknowledgments The authors acknowledge the Science Foundation of Lithuanian University of Health Sciences.

\section{References}

1. Task force of the European Society of Cardiology and the North American Society of Pacing and Electrophysiology (1996) Heart rate variability: standards of measurement, physiological interpretation, and clinical use. Eur Heart J 17:354-381

2. Becker M, Bilke E, Kühl H, Katoh M, Krammann R, Franke A, Bücker A, Hanrath P, Hoffmann R (2006) Analysis of myocardial deformation based on pixel tracking in $2 \mathrm{D}$ echocardiographic images allows quantitative assessment of regional left ventricular function. Heart 92:1102-1108

3. Chen SA, Chiang CE, Tai CT, Cheng CC, Chiou CW, Lee SH, Ueng KC, Wen CZ, Chang SM (1996) Complications of diagnostic electrophysiological studies and radiofrequency catheter ablation in patients with tachyarrhythmias: an eight-year survey 3,966 consecutive procedures in a tertiary referral center. Am J Cardiol 77:43-46

4. D'hooge J (2007) Principles and different techniques for speckle tracking. In: Marwick TH, ChM Yu, Sun JP (eds) Myocardial imaging tissue Doppler and speckle tracking 2007. Blackwell Futura, USA, pp 17-25

5. Di Salvo G, Pacileo G, Castaldi B, Gala S, Morelli C, D'Andrea A, Limongelli G, Del Gaizo F, Merlino E, Russo MG, Calabro R (2009) Two-dimensional strain and atrial function: a study on patients after percutaneous closure of atrial septal defect. Eur J Echocardiogr 10:256-259

6. Di Salvo G, Pacileo G, Del Giudice EM, Natale F, Limongelli G, Verrengia M, Rea A, Fratta F, Castaldi B, Gala S, Coppola F, Russo MG, Caso P, Perrone L, Calabro R (2008) Atrial mycardial deformation properties in obese nonhypertensive children. J Am Soc Echocardiogr 21:151-156

7. Ericson CC, Walsh EP, Triedman JK, Saul JP (1994) Efficacy and safety of radiofrequency ablation in infants and young children $<18$ months of age. Am J Cardiol 74:944-947

8. Guo H, Wang P, Xing Y, Peng F, Jiang J, Yang B, You B, Qiu Y, Lee JD (2007) Delayed injury of autonomic nerve induced by radiofrequency catheter ablation. J Electrocardiol 40:355. e1-355.e4

9. Kanjwal K, Karabin B, Sheikh M, Kanjwal Y, Grubb BP (2010) New-onset postural orthostatic tachycardia syndrome following ablation of AV node reentrant tachycardia. J Interv Card Electrophysiol 29:53-56

10. Kocovic DZ, Harada T, Shea JB, Soroff D, Friedman PL (1993) Alterations of heart rate and of heart rate variability after radiofrequency catheter ablation of supraventricular tachycardia. Circulation 88:1671-1681

11. Kugler JD, Danford DA, Houston KA, Felix G, the other participating members of the pediatric radiofrequency ablation registry of the Pediatric Electrophysiology Society (2002) Pediatric radiofrequency catheter ablation registry success, fluoroscopy time, and complication rate for supraventricular tachycardia:comparison of early and recent eras. J Cardiovasc Electrophysiol 13:336-341

12. Lang RM, Bierig M, Devereux RB, Flachskampf FA, Foster E, Pellikka PA, Picard MH, Roman MJ, Seward J, Shanewise J, Solomon S, Spencer KT, St John Sutton M, Stewart W, American Society of Echocardiography's Nomenclature, Standards Committee; Task Force on Chamber Quantification; American College of Cardiology Echocardiography Committee; American Heart Association; European Association of Echocardiography, European Society of Cardiology et al (2005) Recommendations 
for chamber quantification: a report from the American Society of Echocardiography's Guidelines and Standards Committee and the Chamber Quantification Writing Group, developed in conjunction with the European Association of Echocardiography, a Branch of the European Society of Cardiology. J Am Soc Echocardiogr 18:1440-1463

13. Mukherjee R, Parkhurst AM, Mingoia JT, Sweterlitsch SE, Leiser JS, Escobar P, Spinale FG, Saul JP (2004) Myocardial remodeling after discrete radiofrequency injury: effects of tissue inhibitor of matrix metalloproteinase-1 gene deletion. Am J Physiol Heart Circ Physiol 286:1242-1247

14. Psychari SN, Theodorakis GN, Koutelou M, Livanis EG, DTh Kremastinos (1998) Cardiac denervation after radiofrequency ablation of supraventricular tachycardias. Am J Cardiol 81: 725-731

15. Saul JP, Hulse JE, Papagiannis J, van Praagh R, Walsh EP (1994) Late enlargement of radiofrequency lesions in infant lambs: implications for ablation procedures in small children. Circulation 90:492-499

16. Sehra R, Hubbard JE, Straka SP, Fineberg NS, Zipes DP, Englestein ED (1999) Effect of radiofrequency catheter ablation of accessory pathways on autonomic tone in children. Cardiol Young 9:377-383

17. Sengupta PP, Krishnamoorthy VK, Korinek J, Narula J, Vannan MA, Lester SJ (2007) Left ventricular form and function revisited: applied translation science to cardiovascular ultrasound imaging. J Am Soc Echocardiogr 20:539-551

18. Sirbu C, Herbots L, D'hoog J, Claus P, Marciniak A, Langeland T, Bijnens B, Rademakers FE, Sutherland GR (2006) Feasibility of strain and strain rate imaging for the assessment of regional left atrial deformation: a study in normal subjects. Eur J Echocardiogr 7:199-208

19. Sztajzel JM, Vinolas X, Sobral J, Dumaresq L, Boveda S, Torner P, Oter R, Bayes de Luna A (1997) Heart rate variability early after successful radiofrequency catheter ablation of left and right sided accessory pathways and after selective ablation of the slow pathway. Ann Noninvas Electrocardiol 2:362-369

20. Telagh R, Hui W, Abd El Rahman M, Lange PE, Abdul-Khaiq H (2008) Assessment of regional atrial function in patients with hypertrophic cardiomyopathies using tissue Doppler imaging. Pediatr Cardiol 29:301-308

21. Van Hare GF, Chiesa NA, Campbell RM, Kanter RJ, Cecchin F (2002) Atrioventricular nodal reentrant tachycardia in children: effect of slow-pathway ablation on fast-pathway function. J Cardiovasc Electrophysiol 13:203-209

22. Vianna-Pinton R, Moreno CA, Baxter CM, Lee KS, Tsang TS, Appleton CP (2009) Two-dimensional speckle-tracking echocardiography of the left atrium: feasibility and regional contraction and relaxation differences in normal subjects. J Am Soc Echo 22:299-305 